\title{
Intelligent Electronic Device Functionality and Interfacing: An Experimental Examination of Smart Grid
}

\author{
Sanjay Kumar, Arvind Kumar Singh, Md. Abul Kalam
}

\begin{abstract}
: the intelligence electronic devices are the devices like voltage regulators, circuit breaker controllers, , protection relays which are based on microprocessor. They have ability to communicate using serial communication with other devices. The research work include study of electrical signals, functionality and application of IED in smart grid.
\end{abstract}

Index Terms: microprocessor; IED; functionality; electrical interfacing.

\section{INTRODUCTION}

For power system application communication is very important. Now in last decades to enhance the control and protection of communication several methods are developed. These techniques also mange the effect of distributed generation [1], for restoration and fast-acting protection enabling [2][3], and for integrity and monitoring of wide area system [4] [5]. For these methods the IEC 61850 standard use can provide many benefits. As using a standardized data model and high-speed Ethernet communications, vendor interoperability and standardized configuration methodology is provided [7].

for communication it is require Numerous kind of power intensity framework insurance exceptionally stringent, explicitly: low jitter, low latency and symmetrical latency [7]. to provide dedicated bandwidth and to minimize jitter time division multiplexing (TDM) has been used. when multiple services like data acquisition (SCADA), supervisory control, voice telephony, video surveillance, and phasor evolution of unit data TDM systems make inefficient use of available bandwidth and they act as inherently inflexible [8]

To enable advanced power automation the intelligent electronic device (IED) added to industrial control systems (ICS).

In monitoring of power, communication, metering and controlling many types of IED are used [9].

Some business control system using IED like distributed control systems (DCS) or supervisory control and data acquisition (SCADA. As a part of the system the IED can use in many processes like:

Revised Version Manuscript Received on 16 September, 2019.

Sanjay Kumar Ph.D Scholar, NERIST Arunachal Pradesh EE Dept. Email - sanjay07302258mtech@gmail.com

Prof. Arvind Kumar Singh (Professor), EE Dept. NERIST Arunachal Pradesh Email- singharvindk67@gmail.com

Dr. Md.Abul Kalam (Associate professor) BIT sindri jharkhand, EmailKalam.ee@bitsindri.ac.in
1. Plants water treatment

2. Management of water

3. Fertilizer and Agrochemical

4. Chemical plants

5. Plant's Sewage treatment

6. Mines and metal

7. Power plan and Boiler controls

8. Manufacturing of Automobile

9. Process plants of Metallurgical

10. Paper miles and pulp

11. Control of quality

12. Refineries and Petrochemical (oil)

13. Food processing

14. Manufacturing of Pharmaceutical

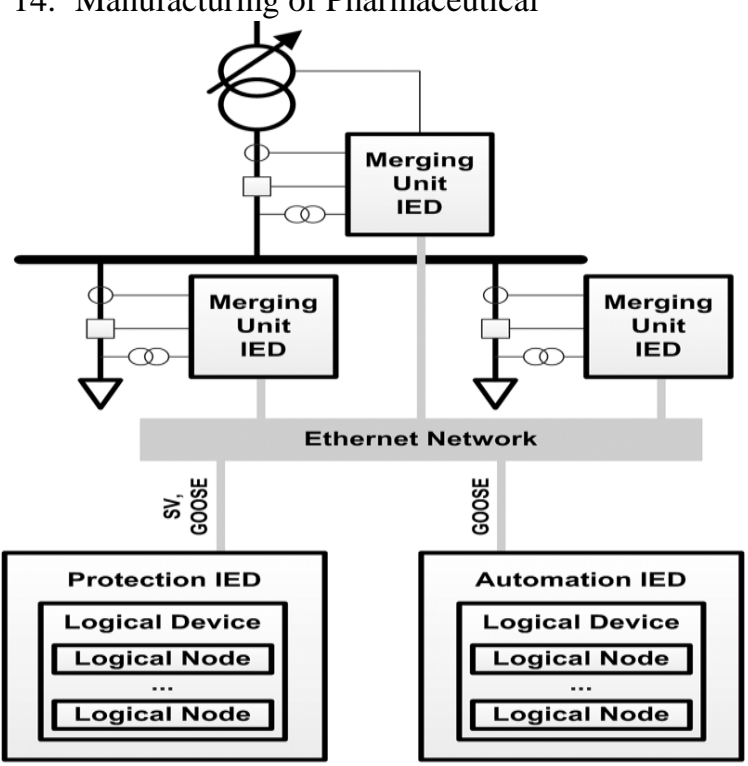

Figure 1: IED diagram

\section{ELECTRICAL INTERFACING}

All possible interfacing of electrical components of an Intelligent Electronic Device are showing in figure 2 [10]. 


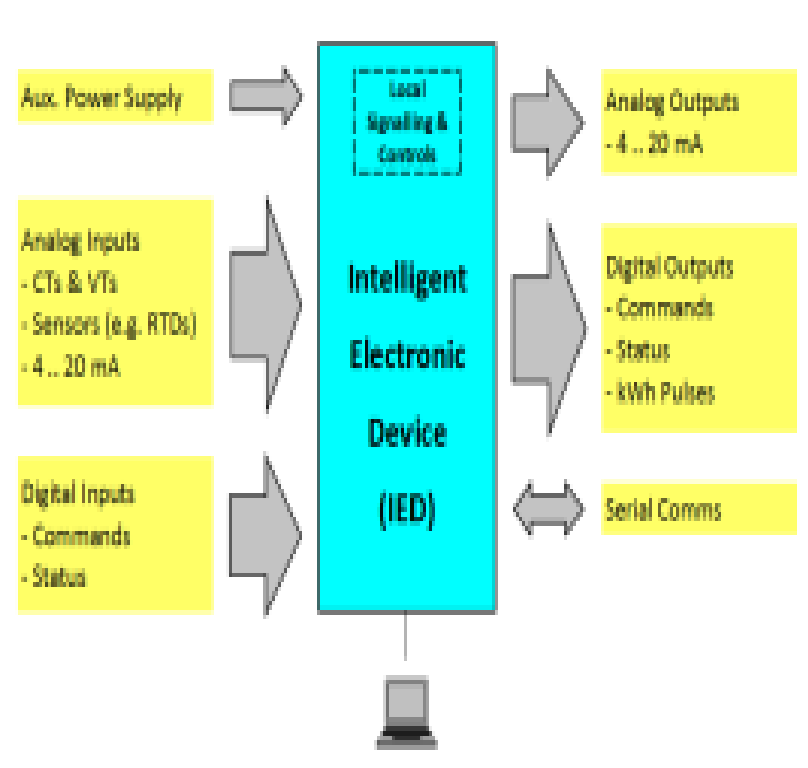

Figure 2: Intelligent Electronic Device electrical interfacing

Analog inputs: Voltage regulator and Protection relays always available with input of voltage and current transformer. The devices can also provide $4 . .20 \mathrm{~mA}$ or sensor inputs input like sensors for temperature. Specification of secondary frequency and current before ordering is necessary in some IEDs. It is important to correct the phase of sensing current and voltage and it should flow in right direction.

Analog outputs: with transducer outputs like $0 . .10 \mathrm{~V}$ or $4 . .20 \mathrm{~mA}$ are provided by some IEDs. Generally these outputs are used as programmable. This output can be active or passive type of output. The output of passive type needed power supply externally.

Digital inputs: for digital input some IEDs needed potential-free contacts. As a logical 1 some IEDs recognize negative or positive power supply voltage. The digital input can be considered as status information or as a command.

Digital outputs: the digital output can change through solid state contacts or change-over contacts or they can potential free normally closed or normally open. Due to significant differences the switching capability of the output contacts is should be checked. The digital output can be considered as status information or as a command.

Serial communication ports: for serial communication like Optical, ethernet (RJ45), RS 485 etc serial communication is required. For local communication with a computer or a laptop the IEDs are also provided with USB or RS 232.

Auxiliary power supply: IED always need an auxiliary power supply although older voltage regulators and protection relays may not need auxiliary supply.

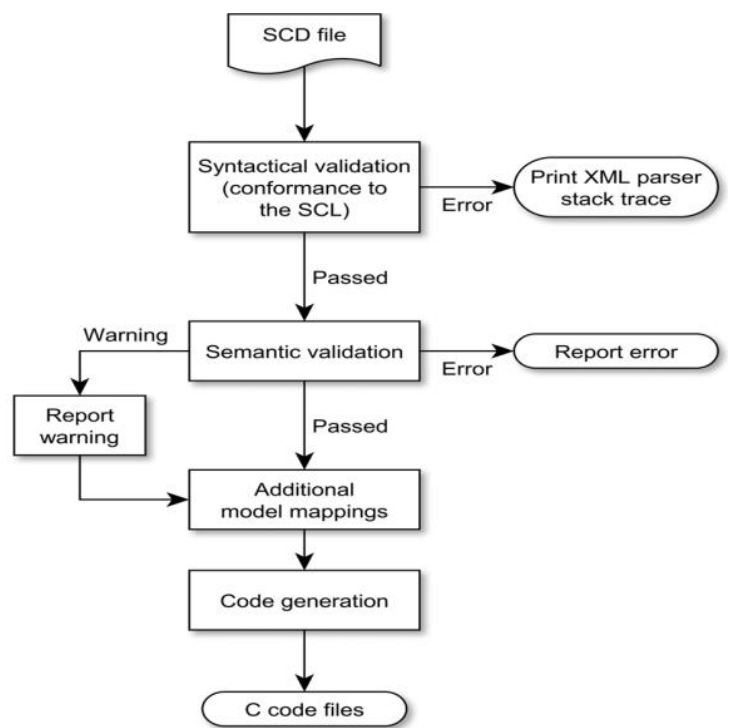

Figure 3: code generation an overall validation process

\section{FUnCTIONALITY OF IED}

The extended version of IED functionality is divided in following categories:

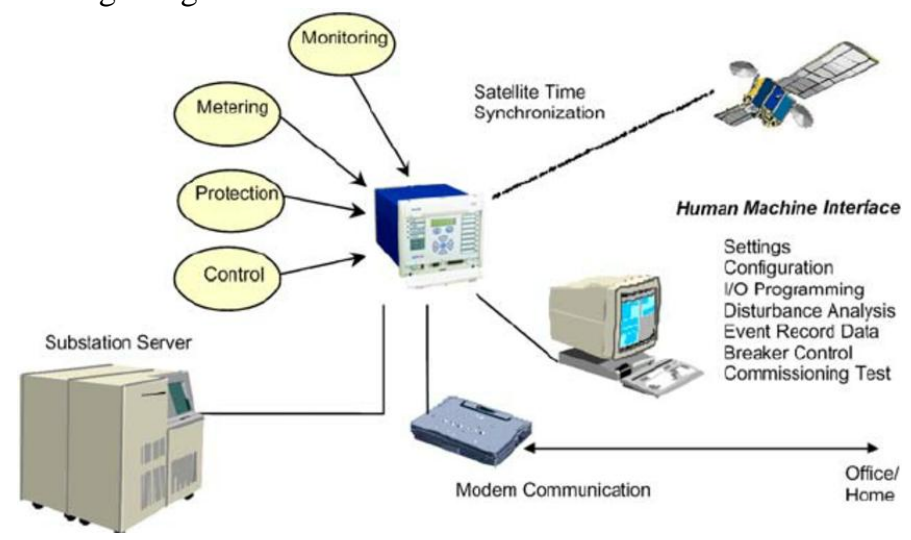

Figure 4: IED functionality

\section{Logics and control functions:}

These types of elements control logics in circuit breakers and control loops in voltage regulators.

\section{Monitoring:}

Every IED should have monitoring of auxiliary power supply and monitoring of internal self-supervision. If IED is well operating then a "healthy" output or a "watch-dog" will close to it. It is require to monitoring of event recording, analog sensing inputs, trip circuit supervision etc.

\section{Protection:}

To protect a feeder, transformer, motor and generator, the functionality of IED include all functions of protection.

\section{Serial communication:}

Some protocol like Profibus, Modbus TCP, Modbus RTU could support by IEDs. The modern IEC 61850 standard created by IED in order to enable interoperation of IEDs from various vendors. 


\section{Metering:}

Metering value like neutral current (A), residual voltage (V), harmonics, energy (kWh, KVArh), phase currents (A), line voltages $(\mathrm{V})$, disturbance recording, voltages $(\mathrm{V})$, analog channels are contains with many IEDs. With output of programmable transducer some IEDs are also provided.

\section{MANAGING INTELLIGENT ELECTRONIC DEVICES}

The example of intelligence electronic devices management is shown in figure 5. Here several IEDs are managed with several controlling units.

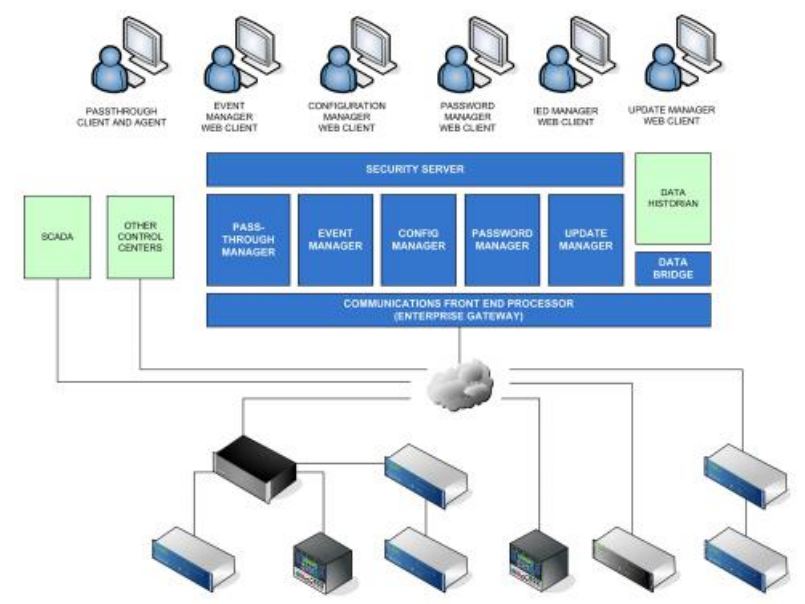

Figure 5: managemnet of IED

\section{A MICROGRID CONTROL AND PROTECTION}

The microgrid with low power use to demonstrate the platform that described. Including controlling and protecting several challenges are there. Major challenge is the fault detecting. During unplanned islanding events when there is high presence of maintaining system and converter-interfaced to resolve these challenges communication is needed. in this way for control and protection microgrids are good option for the use of IEC 61850.

Figure 6 present a microgrid system. it shows that microgrid has three area that are interconnected to each other. That is DG, Local load and single connection to the grid. On the electrical distribution network during faults to guarantee continuity microgrid can be operated in islanded mode or in grid-connected. To ensure the stability of the islanded power system it is critical to have a control system during the change from grid-connected to islanded operation.

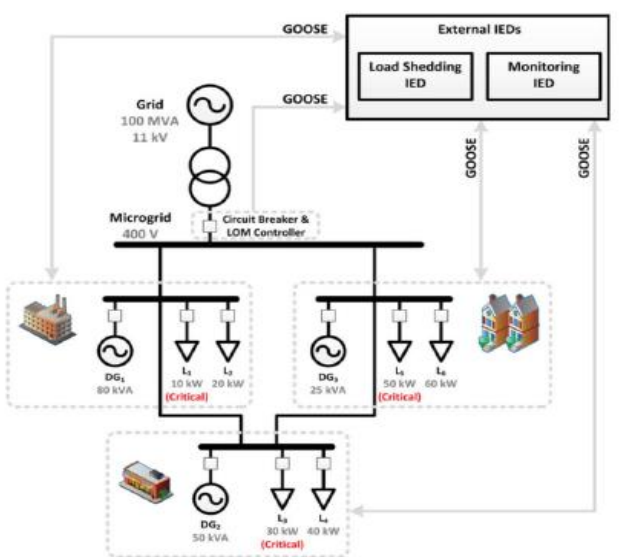

Figure 6: prototype IEDs and Microgrid system

\section{HARDWARE IN THE LOOP DEMONSTRATION}

Under numerous potential situations Hardware in the loop demonstration is an amazing system for testing genuine gadgets. The figure 8 shows the equipment on the up and up course of action for the investigations. For a two line terminal development of differential protection done by Two commercially-available current differential protection relays.

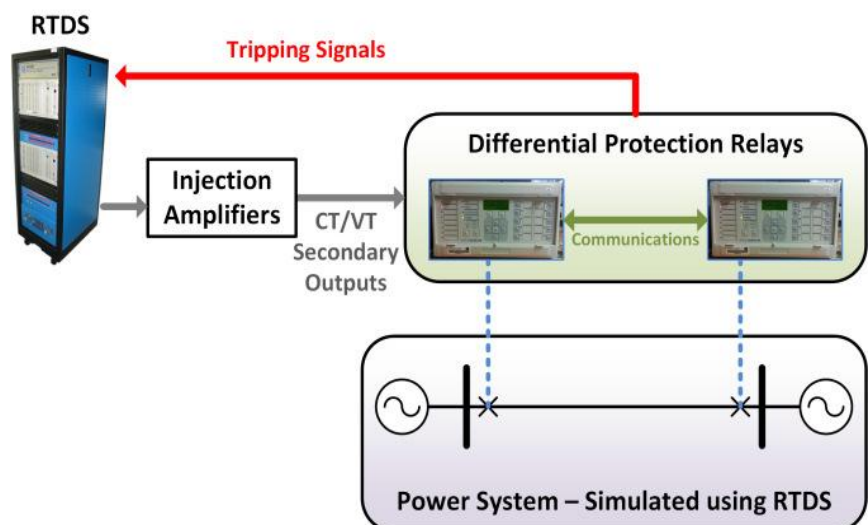

Figure7: In loop demonstration overview of hardware

\section{a. Integrating IP/MPLS Communications}

\section{IEEE C37.94}

For differential security in examination support IEEE C37.94 interchanges the protection relays used. Utilizing business IP/MPLS administration collection switches the IP/MPLS system is actualized. To the protection relays for direct connection Each IP/MPLS router is fitted with a teleportation interface card and voice interface card..

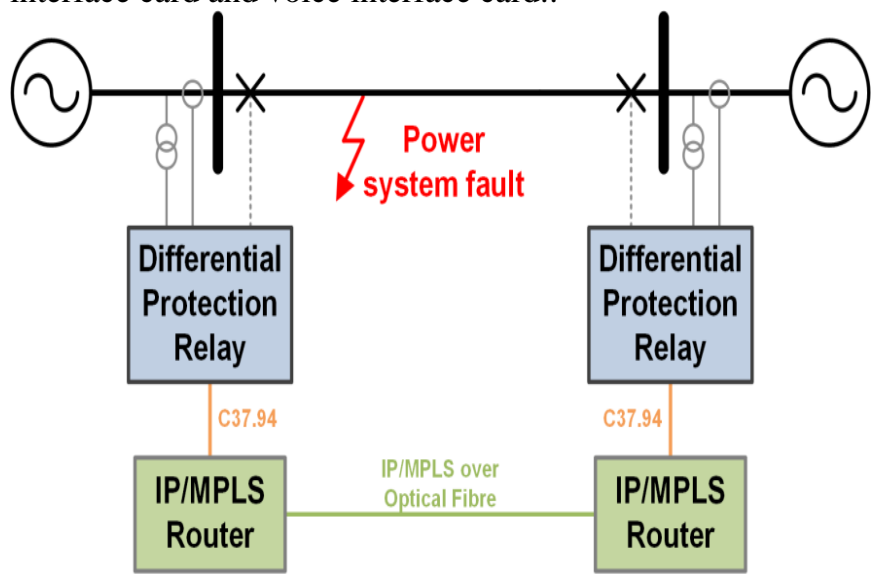

Figure 8: for differential protection network of IP/MPLS

\section{b. IEC 61850-9-2 Sampled Values}

For giving transport bar security the substation local area networks like LANs generally using IEC 61850-9-2 SV communications. Using IP/MPLS for wide-area SV communications this explores the potential 


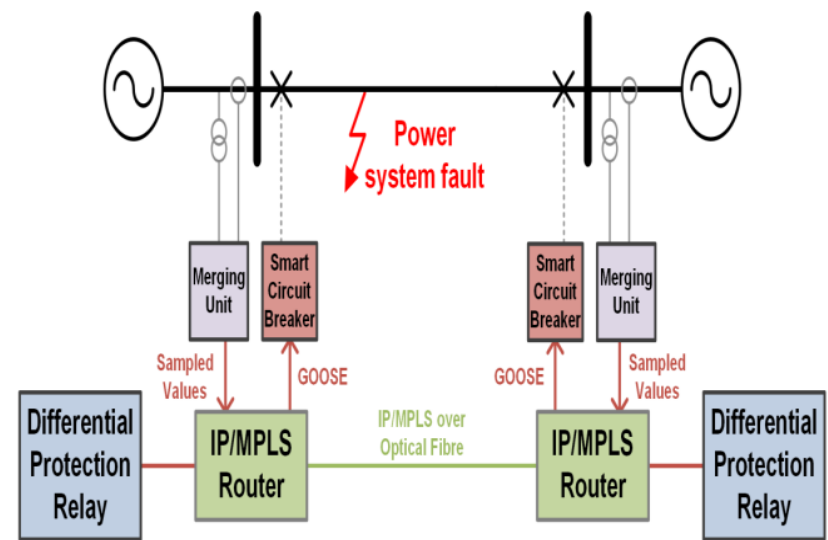

Figure 9: over IP/MPLS using GOOSE and SV Differential protection

\section{SMart Grid Evolution: A NeW Generation OF INTELLIGENT ELECTRONIC DEVICES}

To make a more efficient, smarter electrical power grid the evolution of advanced technologies can be consider as "smart grid". The main objective to develop these technologies is to solve the complex problems that are facing by grid systems [11].

The previous grid devices cannot support the demands of modern energy, changing network prerequisites and measures, increments in conveyed vitality sources, with an utilization case model intended to help the necessities of substantial apparatus and lights alone. In this way for present day progressions like electric vehicles, glaring lights or computers have lack of support. The grid is depending on closed hardware and software platforms and vendor-defined this is very large. To get as standards evolve and grid requirements that make it very challenging to accept.

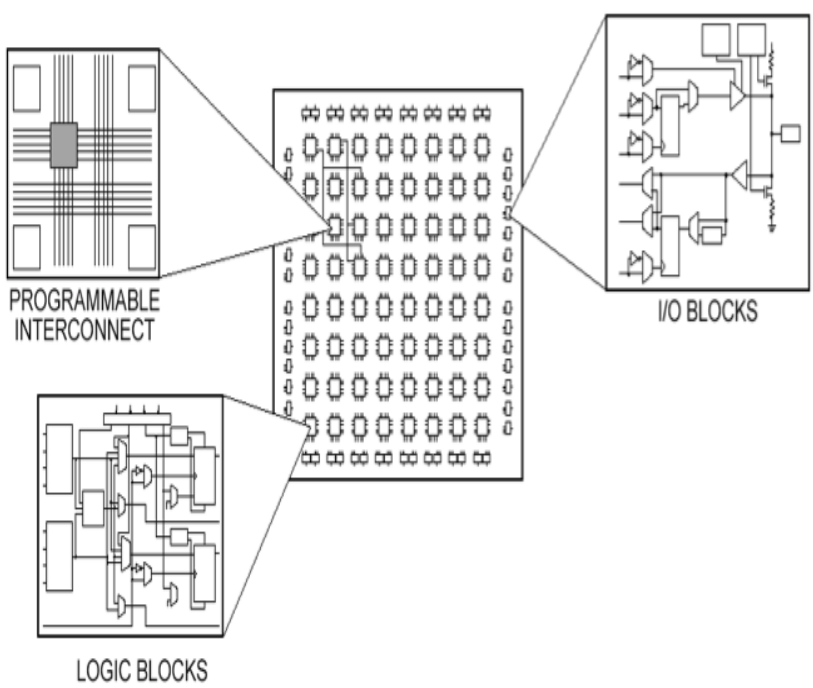

Figure 10: FPGA circuit

By accomplishing more per clock cycle and breaking the paradigm of sequential execution FPGAs enhance the computing power of digital signal processors (DSPs) and computer processors. FPGAs provide specialized functionality and faster response times to intently coordinate application necessities with the capacity to control data sources and yields (I/O) at the equipment level.

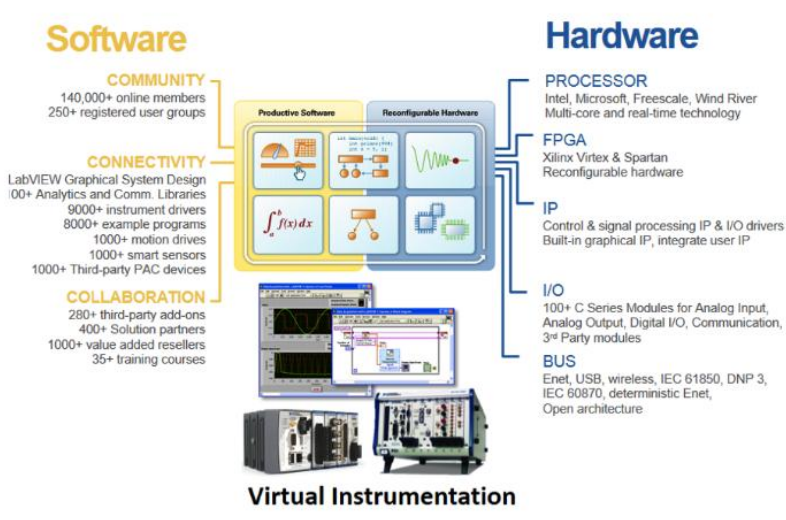

Figure 11: Instrumentation virtuality

\section{CONCLUSION}

For power framework application correspondence is significant. Presently in decades ago to improve the control and insurance of correspondence a few strategies are created. These procedures additionally mange the impact of dispersed age, for rebuilding and quick acting assurance empowering, and for trustworthiness and checking of wide territory system. The intelligence electronic devices are the gadgets like voltage controllers, electrical switch controllers, insurance transfers which depend on microchip. They have capacity to convey utilizing sequential correspondence with different gadgets. The exploration work incorporates investigation of electrical sign, usefulness and utilization of IED in keen framework.

\section{ACKNOWLEDGMENT}

It is optional. The preferred spelling of the word "acknowledgment" in American English is without an "e" after the "g." Use the singular heading even if you have many acknowledgments. Avoid expressions such as "One of us (S.B.A.) would like to thank ... ." Instead, write "F. A. Author thanks" Sponsor and financial support acknowledgments are placed in the unnumbered footnote on the first page.

\section{REFERENCES}

1. Apostil's N. Milioudis, Student Member, IEEE, Georgios T. Andreou, Member, IEEE, and Dimitris P. Labridis, Senior Member "Detection and Location of High Impedance Faults in Multiconductor Overhead Distribution Lines Using Power Line Communication Devices" IEEE TRANSACTIONS ON SMART GRID, VOL. 6, NO. 2 MARCH 2015.

2. Ratan Das, Mital Kanabar, Vice Chair Bethlehem, PA USA Markham, ON Canada Centralized Substation Protection and Control, IEEE PES volume5. Dec.2015.

3. M. Chandran, S. Ravindra Kumar, Dr. P. Somasundaram "Smart and Adaptive over Current Protection for Distribution System with Distributed Generation”. IJAREEIE Vol. 3, Special Issue 2, April 2014.

4. Georgios T.Andreou "Enhanced Protection Scheme for Smart Grids Using Power Line Communications Techniques, IEEE TRANSACTIONS ON SMART GRID, VOL. 3, and NO. 4 DECEMBER 2012.

5. M. M. Eissa, Senior Member, IEEE, Elshahat Masoud, and M. Magdy Mohamed Elanwar "A Novel Back Up Wide Area Protection Technique for Power Transmission Grids Using Phasor Measurement Unit” IEEE TRANSACTIONS ON POWER DELIVERY, VOL. 25, NO. 1, JANUARY 2010

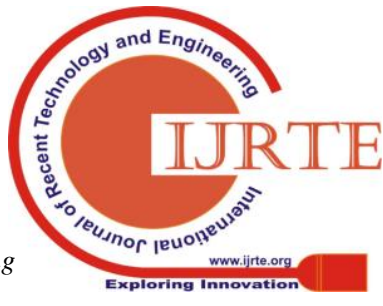


6. F. Coffele, S. M. Blair, C. D. Booth, J. Kirkwood, and B. Fordyce, "Demonstration of Adaptive Over-current Protection Using IEC 61850 Communications," in CIRED, 2013.

7. S. M. Blair and C. D. Booth, "Real-time teleprotection testing using IP/MPLS over xDSL," University of Strathclyde, 2013.

8. S. M. Blair, F. Coffele, C. D. Booth, and G. M. Burt, "An Open Platform for Rapid- Prototyping Protection and Control Schemes with IEC 61850,” IEEE Trans. Power Deliv., vol. 28, no. 2, pp. 1103-1110, 2013.

9. A.Dusa, G. Deconinck, and R. Belmans, "Communication system for intelligent residential electrical installations," in Proceedings of IEEE Power Systems Conference and Exhibition (PSCE-2004), New York City, USA, Oct. 10-13, 6 pages.

10. J. Zhu, "Web services provide the power to integrate," IEEE Power and Energy Magazine, vol. 1, pp. 40-49, Nov.-Dec. 2003.

11. Rachel Denton, "Smart Grid Evolution: A New Generation of Intelligent Electronic Devices", March 6, 2014. 